\title{
Impact of brown and clear carbon on light absorption enhancement, single scatter albedo and absorption wavelength dependence of black carbon
}

\author{
D. A. Lack ${ }^{1,2}$ and C. D. Cappa ${ }^{3}$ \\ ${ }^{1}$ NOAA Earth System Research Laboratory, Chemical Sciences Division, 325 Broadway, Boulder, CO 80304, USA \\ ${ }^{2}$ Cooperative Institute for Research in Environmental Sciences, University of Colorado, 216 UCB, Boulder, CO 80309, USA \\ ${ }^{3}$ Department of Civil and Environmental Engineering, University of California, Davis, California 95616, USA
}

Received: 21 November 2009 - Published in Atmos. Chem. Phys. Discuss.: 15 January 2010

Revised: 17 April 2010 - Accepted: 1 May 2010 - Published: 6 May 2010

\begin{abstract}
The presence of clear coatings on atmospheric black carbon $(B C)$ particles is known to enhance the magnitude of light absorption by the $B C$ cores. Based on calculations using core/shell Mie theory, we demonstrate that the enhancement of light absorption $\left(E_{\mathrm{Abs}}\right)$ by atmospheric black carbon $(B C)$ when it is coated in mildly absorbing material $\left(C_{\text {Brown }}\right)$ is reduced relative to the enhancement induced by non-absorbing coatings $\left(C_{\text {Clear }}\right)$. This reduction, sensitive to both the $C_{\text {Brown }}$ coating thickness and imaginary refractive index $(R I)$, can be up to $50 \%$ for $400 \mathrm{~nm}$ radiation and $25 \%$ averaged across the visible radiation spectrum for reasonable core/shell diameters. The enhanced direct radiative forcing possible due to the enhancement effect of $C_{\text {Clear }}$ is therefore reduced if the coating is absorbing. Additionally, the need to explicitly treat $B C$ as an internal, as opposed to external, mixture with $C_{\text {Brown }}$ is shown to be important to the calculated single scatter albedo only when models treat $B C$ as large spherical cores $(>50 \mathrm{~nm})$. For smaller $B C$ cores (or fractal agglomerates) consideration of the $B C$ and $C_{\text {Brown }}$ as an external mixture leads to relatively small errors in the particle single scatter albedo of $<0.03$. It has often been assumed that observation of an absorption Angström exponent $(A A E)>1$ indicates absorption by a non- $B C$ aerosol. Here, it is shown that $B C$ cores coated in $C_{\text {Clear }}$ can reasonably have an $A A E$ of up to 1.6, a result that complicates the attribution of observed light absorption to $C_{\text {Brown }}$ within ambient particles. However, an $A A E<1.6$ does not exclude the possibility of $C_{\mathrm{Brown}}$; rather $C_{\mathrm{Brown}}$ cannot be confidently assigned un-
\end{abstract}

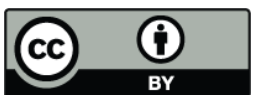

Correspondence to: D. A. Lack (daniel.lack@noaa.gov) less $A A E>1.6$. Comparison of these model results to various ambient $A A E$ measurements demonstrates that large-scale attribution of $C_{\text {Brown }}$ is a challenging task using current in-situ measurement methods. We suggest that coincident measurements of particle core and shell sizes along with the $A A E$ may be necessary to distinguish absorbing and non-absorbing OC.

\section{Introduction}

\subsection{Black carbon and clear coatings}

The absorption of solar radiation by atmospheric black carbon $(B C)$ is thought to lead to positive top-of-atmosphere radiative forcing (i.e. atmospheric warming) about $1 / 4$ of the magnitude of anthropogenic $\mathrm{CO}_{2}$ (IPCC, 2007). Accordingly, the sources, emission strengths and climate impact of $B C$ are a topic of significant research.

The impact of other atmospheric particulate components on $B C$ absorption, in the form of internal mixtures of $B C$ with primary and secondary organic aerosol (POA, SOA) and inorganic salts such at sulfate, has also drawn significant attention (e.g. Bond et al., 2006; Jacobson, 2001; Zhang et al., 2008). This is because the light absorption by an absorbing core can be enhanced when coated with a purely scattering shell (Fuller et al., 1999). The shell acts as a lens and focuses more photons onto the core than would reach it otherwise. This lensing effect has been shown theoretically to increase the absorption by an individual $B C$ particle by $50-100 \%$ for core and shell sizes typical of the atmosphere (Bond et al., 2006) and is thought to have an important influence on the radiative forcing by $B C$ (Jacobson,

Published by Copernicus Publications on behalf of the European Geosciences Union. 
2001). Absorption enhancement due to lensing has been observed for $B C$ particles coated with SOA (Schnaiter et al., 2005) or sulfuric acid (Zhang et al., 2008), for absorbing polystyrene spheres coated with organic material (Lack et al., 2009a), graphite coated with oleic acid or glycerol (Shiraiwa et al., 2009) and for absorbing mineral dust coated in aqueous inorganic material (Lack et al., 2009b). The absorption enhancement, $E_{\mathrm{Abs}}$, is defined as the ratio of the absorption cross section, $\sigma_{\mathrm{Abs}}$, of a coated absorbing particle (usually BC) to an equivalent uncoated particle (see Eq. 1 below).

$E_{\mathrm{Abs}}=\frac{\sigma_{\mathrm{Abs}-\text { Core }- \text { Shell }}}{\sigma_{\mathrm{Abs}-\text { Core }}}$

Evaluation of recent field data of particulate organic matter (OM, including both primary and secondary aerosol) concentrations show that particulate OM is often present with abundances similar to or larger than that of inorganic particulate matter, such as sulfate and nitrate salts (e.g. Zhang et al., 2007). In particular, a large amount of directly emitted OM is internally mixed with $B C$ from sources such as biomass and biofuel combustion (Alexander et al., 2008; Gustafsson et al., 2009; Roden et al., 2006), and $B C$ from internal combustion engines can become thickly coated in condensable material within hours to days of emission (e.g. Quinn et al., 2004). It is therefore reasonable to expect that a significant amount of atmospheric $B C$ is internally mixed with $\mathrm{OM}$, which therefore provides a significant opportunity for absorption enhancement and is thus the focus of current research on the evolution of mixing state of $B C$ (e.g. Moteki et al., 2007; Schwarz et al., 2008).

\subsection{Black carbon and brown coatings}

Emerging research suggests that a variety of particulate OM can absorb radiation, particularly at the shorter visible and UV wavelengths (Adler et al., 2009; Barnard et al., 2008; Dinar et al., 2008; Hoffer et al., 2006; Kirchstetter et al., 2004; Rincon et al., 2009; Roden et al., 2006; Schnaiter et al., 2006; Schwier et al., 2009; Shapiro et al., 2009; Sun et al., 2007; Yang et al., 2009). In fact the mass absorption cross-section (MAC) of this so-called "brown carbon" $\left(C_{\text {Brown }}\right)$ (Andreae and Gelencser, 2006) has been estimated to be of the same order as $B C$ at $400 \mathrm{~nm}$ (Barnard et al., 2008; Clarke et al., 2007). Given the large abundance of particulate OM relative to $B C$ in the atmosphere, this suggests that absorption by $C_{\text {Brown }}$ may be a significant fraction of total atmospheric light absorption (Clarke et al., 2007). Despite the potential contributions of $C_{\text {Brown }}$ to absorption of solar radiation, all theoretical studies to date of the lensing-induced $E_{\mathrm{Abs}}$ have focused solely on the role of non-absorbing coatings. In the present study, we directly address how the presence of $C_{\text {Brown }}$ coatings (i.e. coatings that are not purely scattering) on $B C$ cores influence the magnitude of $E_{\mathrm{Abs}}$.

A wide range of MAC and imaginary RI values for $C_{\mathrm{Brown}}$ $\left(k_{\text {Brown }}\right)$ have been reported in the literature. Reported $k_{\text {Brown }}$ values (at $\sim 550 \mathrm{~nm}$ ) range from 0.002 to 0.27 (Alexander et al., 2008; Hoffer et al., 2006), which compare to a value of ca. 0.71 for pure $B C$ (Bond and Bergstrom, 2006). MACs vary from 0.02 to $2 \mathrm{~m}^{2} \mathrm{~g}^{-1}$ at mid visible wavelengths and from $1-10 \mathrm{~m}^{2} \mathrm{~g}^{-1}$ at $350 \mathrm{~nm}$. These values were derived from field measurements of particulate OM observed from Asian pollution outflow (Yang et al., 2009), African biomass combustion (Kirchstetter et al., 2004), Mexico City pollution (Barnard et al., 2008) and humic-like substances (HULIS) extracted from Amazonian biomass combustion particles (Hoffer et al., 2006). These $C_{\text {Brown }} M A C$ s compare to a $B C M A C$ of ca. $7.5 \mathrm{~m}^{2} \mathrm{~g}^{-1}$ at $550 \mathrm{~nm}$ or ca. $12-13 \mathrm{~m}^{2} \mathrm{~g}^{-1}$ at $\sim 350 \mathrm{~nm}$ (from Adler et al., 2009) and calculated assuming an absorption Angstrom exponent $=1$ and extrapolating from Bond and Bergstrom (2006); see Eq. 2). The large variability in $M A C$ for particulate $O M$ is likely related to the variability in the composition of the $O M$ fraction, which can include HULIS, lignin and polycyclic aromatic compounds (Andreae and Gelencser, 2006).

Attribution of observed atmospheric light absorption to $C_{\text {Brown }}$ is an important step in understanding the overall climate effects of aerosol. Some studies have attempted this attribution based on assumptions as to the wavelength dependence of absorption (e.g. Favez et al., 2009; Yang et al., 2009). It is often assumed that the imaginary $R I$ for $B C$ is wavelength $(\lambda)$ independent and that the absorption crosssection for $B C$ varies as $\lambda^{-1}$ (Bond and Bergstrom, 2006) (discussed further below). The variation of absorption with wavelength is characterized by the absorption Angstrom exponent $(A A E)$, defined as

$A A E=-\left(\frac{\ln \left(\sigma_{\mathrm{Abs}-\lambda_{1}} / \sigma_{\mathrm{Abs}-\lambda_{2}}\right)}{\ln \left(\lambda_{1} / \lambda_{2}\right)}\right)$

where $\sigma_{\mathrm{Abs}}$ is the absorption cross-section (or observed absorption). An $A A E=1$ corresponds to a $\lambda^{-1}$ dependence of absorption. It is thought that $C_{\text {Brown }}$ shows strong deviations from the $\lambda^{-1}$ relationship and it has therefore been assumed that the observation of an $A A E$ larger than 1 is an indication of absorption by $C_{\text {Brown }}$ (or dust if present). However, as mentioned by Gyawali et al. (2009), the $A A E$ of $B C$ cores with $>10 \mathrm{~nm}$ diameter and of $B C$ cores that are coated in scattering shells may deviate from the typically assumed $A A E=1$ relationship. For example, the $A A E$ for $B C$ alone can be greater or less than 1 , depending on the modeled core size. This must be explicitly kept in mind when assigning contributions to light absorption to $C_{\text {Brown }}$.

As research into the absorption properties and ubiquity of $C_{\text {Brown }}$ progresses, it is prudent to consider what the impact of $C_{\mathrm{Brown}}$ is on the lensing-induced absorption enhancement for $B C$. Consider that whereas absorption by a $B C$ core with a purely scattering shell will have contributions to absorption by the core and $E_{\mathrm{Abs}}$ by the lensing effect, a $B C$ core coated in $C_{\text {Brown }}$ will have absorption contributions from the core, the absorbing shell and the $E_{\mathrm{Abs}}$ from the lensing effect 


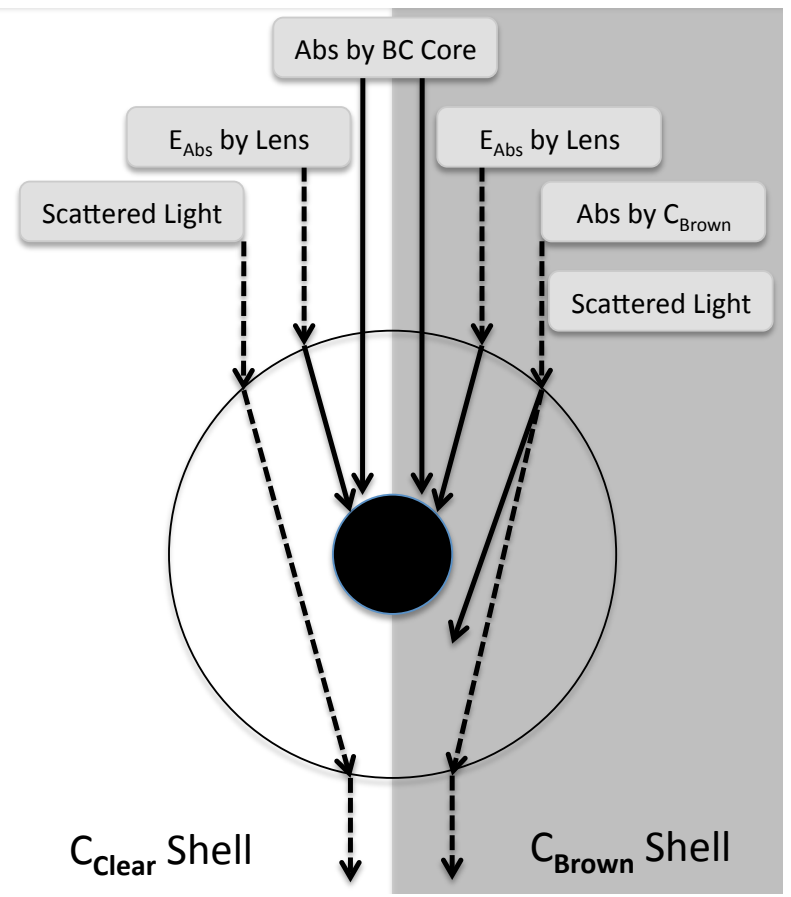

Fig. 1. Schematic of the effect of $C_{\text {Clear }}$ and $C_{\text {Brown }}$ shells on $B C$ absorption.

(see Fig. 1 for a schematic of this effect). Given the different optical properties of $C_{\text {Brown }}$ compared to a purely scattering shell, the $E_{\mathrm{Abs}}$ is very likely to be dependent on the wavelength of light, the absorption properties of the $C_{\text {Brown }}$ and shell thickness. In an effort to address the above issue, we present here a series of calculations performed using coreshell Mie theory (Bohren and Huffman, 1983) wherein we investigate the impact of a slightly absorbing, rather than purely scattering, shell on the absorption enhancement factor, $E_{\mathrm{Abs}}$ and aerosol single scatter albedo (SSA). This modeling study builds on the work of Bond et al. (2006) and we remain consistent with that study by using many of the same terms, modeling parameters and discussion points. We also investigate the impact of $B C$ cores coated in purely scattering shells on the $A A E$ to provide further insight and recommendations for future studies attempting to elucidate the contribution of $B C, C_{\text {Brown }}$ and purely scattering shells.

\section{Modeling}

To model the absorption enhancement impact of $C_{\text {Brown }}$ we remain consistent with the study of Bond et al. (2006) and use a $R I$ for $B C$ of $1.85-0.71 i$ and a real $R I$ of 1.55 for the non-absorbing shell (defined here as a clear coating, $C_{\text {Clear }}$ ). The $B C$ core is modeled as a lognormal $(L N)$ distribution of cores having a geometric standard deviation (GSD) of 1.1 (unless otherwise stated). The "core" and "shell" diameters, $d_{p \text {,core }}$ and $d_{p \text {, shell }}$, refer the central sizes in the $L N$ particle

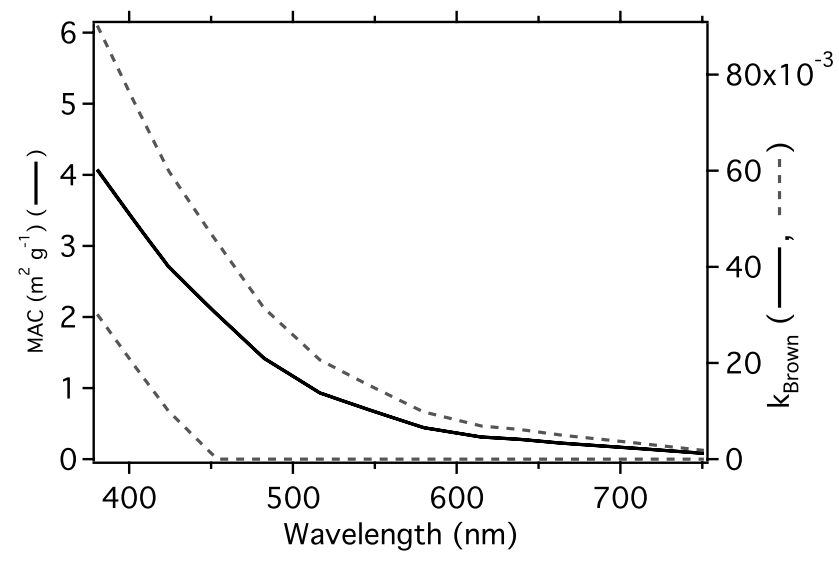

Fig. 2. Wavelength dependent mass absorption cross-section (MAC) of $C_{\text {Brown }}$ with a form as given by Sun et al. (2007) and where the absolute magnitude of the $k_{\text {Brown (solid black line) has }}$ been deduced from Barnard et al. (2008). Dashed lines indicate $k_{\text {Brown }}$ upper and lower bounds for our modeling.

distribution. The core diameter refers to the diameter of the core alone, while the shell diameter is the diameter of the entire particle, i.e. core $+\operatorname{shell}\left(d_{p \text {, shell }}=d_{p \text {,particle }}\right)$. The LN distribution is coated by applying the central shell-to-core diameter ratio to each core of the $L N$ distribution (i.e. the ratio $d_{p \text {, shell }} / d_{p, \text { core }}$ is conserved).

The $R I$ of $C_{\text {Brown }}$ is expected to vary with wavelength and so we model across the visible radiation spectrum (380$750 \mathrm{~nm}$ ). We have also performed some calculations at a specific wavelength of $400 \mathrm{~nm}$ to illustrate a single wavelength impact. Wavelengths around $400 \mathrm{~nm}$ are commonly used in in-situ aerosol optical property measurements. In general, the solar spectrum averaged results are more relevant for the overall climate impacts whereas the single wavelength results will assist in assessing in-situ measurements. Wavelength-dependent $k_{\text {Brown }}$ values have been estimated from literature observations. The SSA of particulate OM was measured by Barnard et al. (2008) to be 0.75 (at $380 \mathrm{~nm}$ ) and is used to calculate $k_{\text {Brown }}$ at $380 \mathrm{~nm}$. To do this we assume a particle diameter of $200 \mathrm{~nm}$, a real $R I$ of 1.55 and calculate the $k_{\text {Brown }}$ (using Mie theory) required to achieve an SSA of 0.75 at $380 \mathrm{~nm}$; the calculated $k_{\text {Brown }}$ is 0.06 at $380 \mathrm{~nm}$. We then apply the form of the MAC vs. wavelength curve modeled by Sun et al. (2007) (and similar to that measured by Kirchstetter et al., 2004) to produce a wavelength dependant $k_{\text {Brown }}$ (Fig. 2). The actual $k_{\text {Brown }}$ remains somewhat uncertain and may vary with location and source. To approximately account for this, we have also investigated the sensitivity of the results to the chosen $k_{\text {Brown }}$ by a) increasing the original $k_{\text {Brown }}$ by $50 \%$ and b) subtracting 0.03 from the original $k_{\text {Brown. }}$. These changes simulate more and less absorbing OM as measured in some studies (Adler et al., 2009; Dinar et al., 2008; Hoffer et al., 2006; Schnaiter et al., 2006) (Fig. 2). 
We also note here that the use of Mie theory assumes spherical particles. There is sufficient evidence that BC, usually fractal when emitted from efficient combustion, can become more compact and the overall particle spherical when coated in other inorganic and organic material (Alexander et al., 2008; Lewis et al., 2009; Zhang et al., 2008). Our modeling mostly deals with coated $B C$ cores. In the limit of thinly coated cores, where fractal $B C$ is more likely, the work of Liu et al. (2008) provides guidance on the differences in absorption for fractal vs. spherical BC. For smaller $(15 \mathrm{~nm})$ and larger $(25 \mathrm{~nm}) B C$ spherule sizes, absorption will likely be overestimated by up to $10 \%$ and underestimated by up to $20 \%$ if represented as spherical. Recent laboratory studies of spherical particles using absorbing cores with non-absorbing coatings showed generally good agreement with predictions from Mie theory for absorption (Shiraiwa et al., 2009; Lack et al., 2009a) and extinction (AboRiziq et al., 2008; Lang-Yona et al., 2010). However, when non-absorbing cores with slightly absorbing coatings were considered the model/measurement agreement for extinction measurements was found to be worse (Lang-Yona et al., 2010). Given the challenges with dealing even with spherical particles, this suggests that the computational results presented here should be considered as a guide to understanding the general influence of $C_{\text {Brown }}$ on aerosol absorption, but that experimental verification will ultimately be needed.

\section{Defining absorption enhancement- $E_{\text {abs }}$}

The $E_{\mathrm{Abs}}$ of a core-shell system is defined as the ratio of absorption cross-sections $\left(\sigma_{\mathrm{Abs}}\right)$ of the coated and uncoated particles (Eq. 1) and here is calculated for all visible wavelengths. The physical interpretation of $E_{\mathrm{Abs}}$ for a $B C$ core with a $C_{\text {Clear }}$ shell is relatively straight forward compared to systems with absorbing shells because the addition of a $C_{\text {Clear }}$ shell leads to an increase in absorption by lensing only. However, when the shell also has an absorbing component, absorption from both the shell material and the lensing effect created by the shell contribute and must be accounted for. Here we distinguish between the contributions from the two $C_{\text {Brown }}$ absorption effects. First, the $\sigma_{\mathrm{Abs}}$ of a homogenous particle (with diameter $\mathrm{d}_{p \text {, shell }}$ ) of $C_{\text {Brown }}$ (e.g. using $\mathrm{k}_{\text {Brown }}$ from Fig. 2) system is calculated across all visible wavelengths. This is repeated for a $C_{\mathrm{Brown}}$ particle with di-

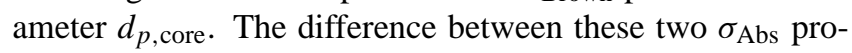
vides a measure of the absorption by the $C_{\mathrm{Brown}}$ coating after accounting for the size dependence of absorption and scattering. This absorption by $C_{\mathrm{Brown}}$ is then subtracted from $\sigma_{\mathrm{Abs}}$ calculated as for step 1 except using a $B C$ core with the same $C_{\text {Brown }}$ coating (and where the core diameter $=$ nonabsorbing core diameter as above, see Table 1 ). The resultant quantity is the absorption by the $B C$ core including lensing (but not absorption) by $C_{\mathrm{Brown}}$, and the calculated $E_{\mathrm{Abs}}$ provides an estimate of the lensing effect of the $C_{\mathrm{Brown}}$. Figure 3

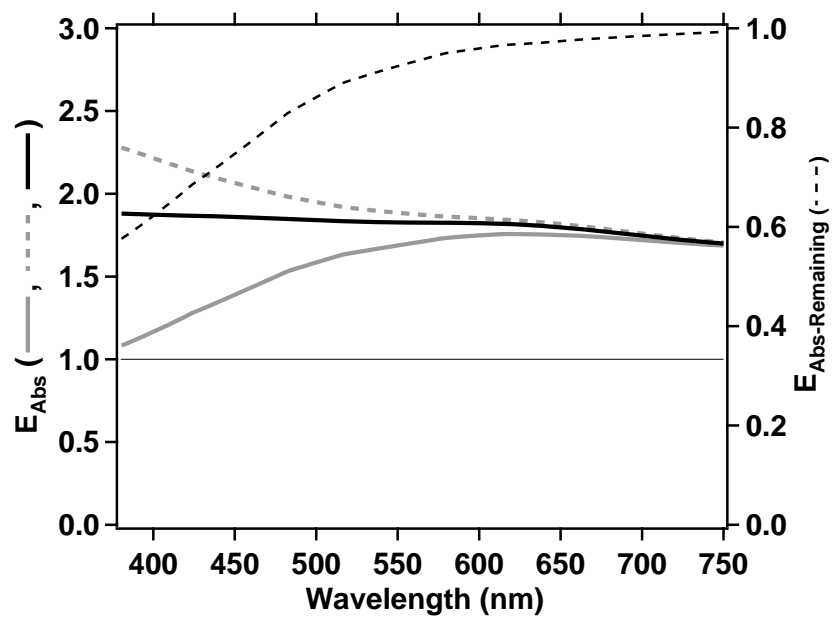

Fig. 3. Example of calculated $E_{\mathrm{Abs}}$ for a $B C$ core and $C_{\mathrm{Clear}}$ shell ( $E_{\mathrm{Abs}-\mathrm{CL}}$, solid black), $B C$ core and $C_{\mathrm{Brown}}$ shell $\left(E_{\mathrm{Abs}-\mathrm{BR}}\right.$, dashed gray) and $B C$ core and $C_{\text {Brown }}$ shell with $C_{\mathrm{Brown}}$ absorption contribution removed ( $E_{\mathrm{Abs}-\mathrm{BR}-\mathrm{X}}$, solid gray). The reduction in the absorption enhancement in going from a clear to an absorbing coating, $E_{\text {Abs-Remaining, }}$, is shown as the dashed black (right axis). This is for a system having a $300 \mathrm{~nm}$ diameter core and a $500 \mathrm{~nm}$ shell diameter.

shows the calculated $E_{\mathrm{Abs}}$ (across all visible wavelengths) for 3 systems; 1) $E_{\mathrm{Abs}-\mathrm{CL}}$ : the "standard" $E_{\mathrm{Abs}}$ for a $C_{\mathrm{Brown}}$ core and $C_{\mathrm{Clear}}$ shell 2) $E_{\mathrm{Abs}-\mathrm{BR}}$ : the $E_{\mathrm{Abs}}$ for a $B C$ core and $C_{\text {Brown }}$ shell including both the absorption and lensing components of the $C_{\mathrm{Brown}}$ and 3) $E_{\mathrm{Abs}-\mathrm{BR}-\mathrm{X}}$ : the $E_{\mathrm{Abs}}$ for a $B C$ core and shell with the absorption contribution of the $C_{\text {Brown }}$ removed as described above.

Based on these definitions (given explicitly in Table 1),

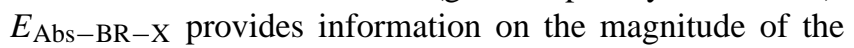
lensing effect of $C_{\mathrm{Brown}}$ only. $E_{\mathrm{Abs}-\mathrm{BR}-\mathrm{X}}$ may differ from $E_{\text {Abs-CL }}$ due to either (i) modification of the photon path through the particle due to the absorbing coating, thus causing fewer (or more) photons to be focused towards the core, or (ii) absorption of photons by the coating material, thus causing fewer photons to reach the core. In this second case, the total absorption by the coated particle will be conserved (i.e. it does not matter whether a photon is absorbed within the shell or the core), but the magnitude of $E_{\mathrm{Abs}}$ has been decreased. When $E_{\mathrm{Abs}-\mathrm{BR}-\mathrm{X}}>1$, this indicates that photons at that wavelength are still being focused onto the core due to the lensing effect. However, when $E_{\mathrm{Abs}-\mathrm{BR}-\mathrm{X}}<1$, this is an indication that the enhancement due to the lensing effect is overwhelmed by absorption by the coating material. In the limit of a strongly absorbing, thick coating no photons will make it to the core and $E_{\mathrm{Abs}-\mathrm{BR}-\mathrm{X}} \rightarrow 0$.

As an illustrative example, we consider a system with a $B C$ core diameter of $300 \mathrm{~nm}$ and a shell diameter of $500 \mathrm{~nm}$. For these conditions, it is found that $E_{\mathrm{Abs}-\mathrm{CL}}$ is essentially wavelength independent with a value of ca. 1.8 (Fig. 3). In contrast, the $E_{\mathrm{Abs}-\mathrm{BR}}$ varies between 1.7 and 2.4 across 
Table 1. Parameter descriptions.

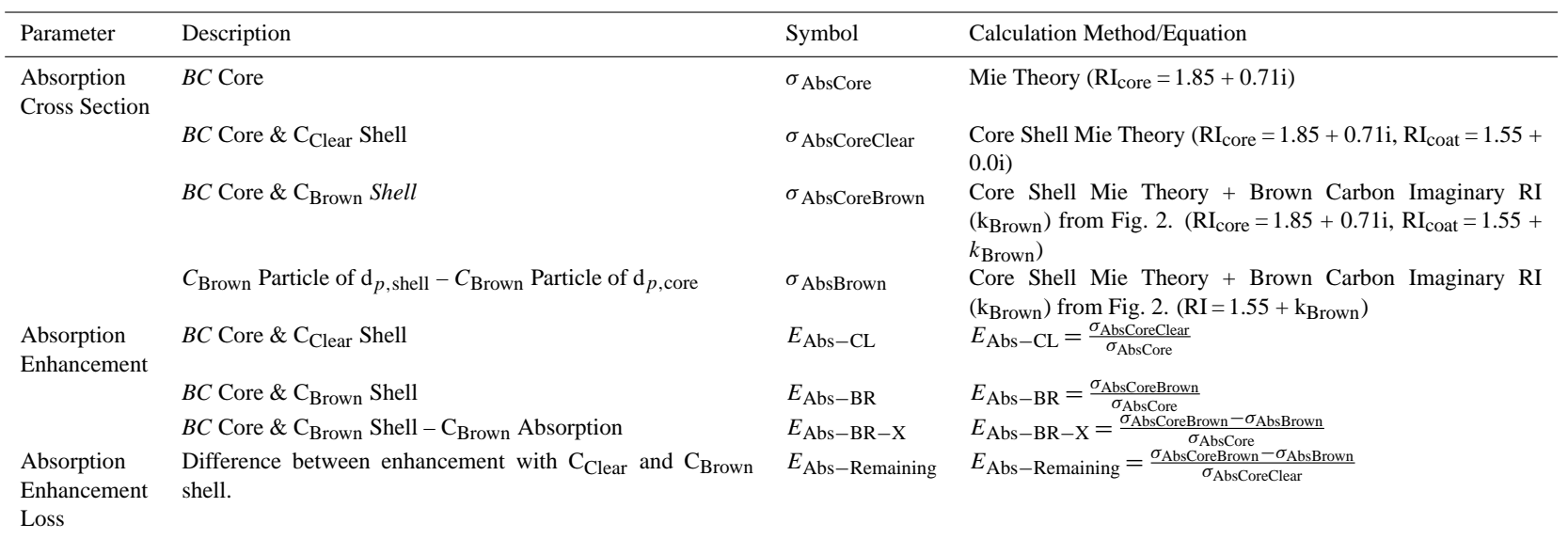

Table 2. Central core and shell diameters from the five $E_{\mathrm{Abs}}$ regimes of Bond et al. (2006)

\begin{tabular}{lll}
\hline $\begin{array}{l}\text { Bond et al. (2006) } \\
\text { Regime \# }\end{array}$ & $\begin{array}{l}\text { Central Core } \\
\text { Diameter } \\
(\mathrm{nm})\end{array}$ & $\begin{array}{l}\text { Central Shell } \\
\text { Diameter } \\
(\mathrm{nm})\end{array}$ \\
\hline 1 & 25 & 1500 \\
2 & 100 & 1500 \\
3 & 60 & 330 \\
4 & 300 & 400 \\
5 & 300 & 1500 \\
\hline
\end{tabular}

the visible spectrum. This larger $E_{\mathrm{Abs}-\mathrm{BR}}$ results from absorption by $C_{\text {Brown }}$. When the absorption of the $C_{\text {Brown }}$ shell is accounted for we see that the adjusted enhancement, $E_{\mathrm{Abs}-\mathrm{BR}-\mathrm{X}}$, is reduced below the $E_{\mathrm{Abs}-\mathrm{CL}}$ at all wavelengths. The wavelength dependence of $E_{\mathrm{Abs}-\mathrm{BR}}$ derives from the wavelength dependence of the $C_{\text {Brown }}$ absorption, described above. The reduction in $E_{\mathrm{Abs}}$ for any conditions is characterized by calculating the remaining enhancement, $E_{\text {AbsRemaining, }}$ as defined in Table 1 .

\section{Results}

In this section we use the definitions of the five core/shell diameter regimes given by Bond et al. (2006) to provide insights into the ' $E_{\mathrm{Abs}}$ lost' (presented as $E_{\mathrm{Abs}-\text { Remaining }}$ ) that results from the coating being $C_{\mathrm{Brown}}$ rather than $C_{\mathrm{Clear}}$. Of these Bond regimes the most common expected in the atmosphere are regimes 3 and 4 (see Fig. 4). Regime 3 corresponds to particles with core diameters $<175 \mathrm{~nm}$ and thick shells (relative to the core size, with $d_{\text {core }} / d_{\text {shell }}>0.55$ but $d_{\text {shell }}>500 \mathrm{~nm}$ ) while regime 4 corresponds to thin shells
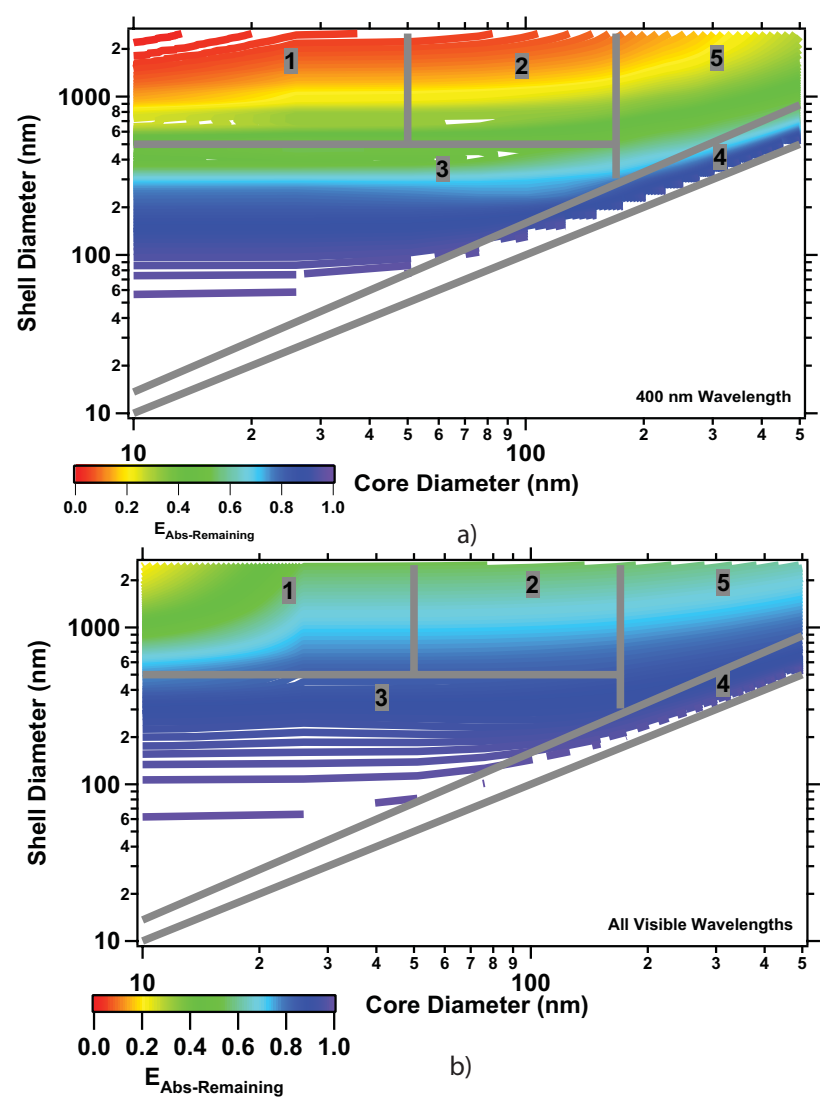

Fig. 4. (a) Calculated $E_{\mathrm{Abs}-\text { Remaining for different } B C \text { core and }}$ $C_{\text {Brown }}$ shell diameters at $400 \mathrm{~nm}$ wavelength. Regime numbers from Bond et al. (2006) and position of central values used for these regimes also shown. (b) Same as (a) but integrated over all visible light wavelengths. 

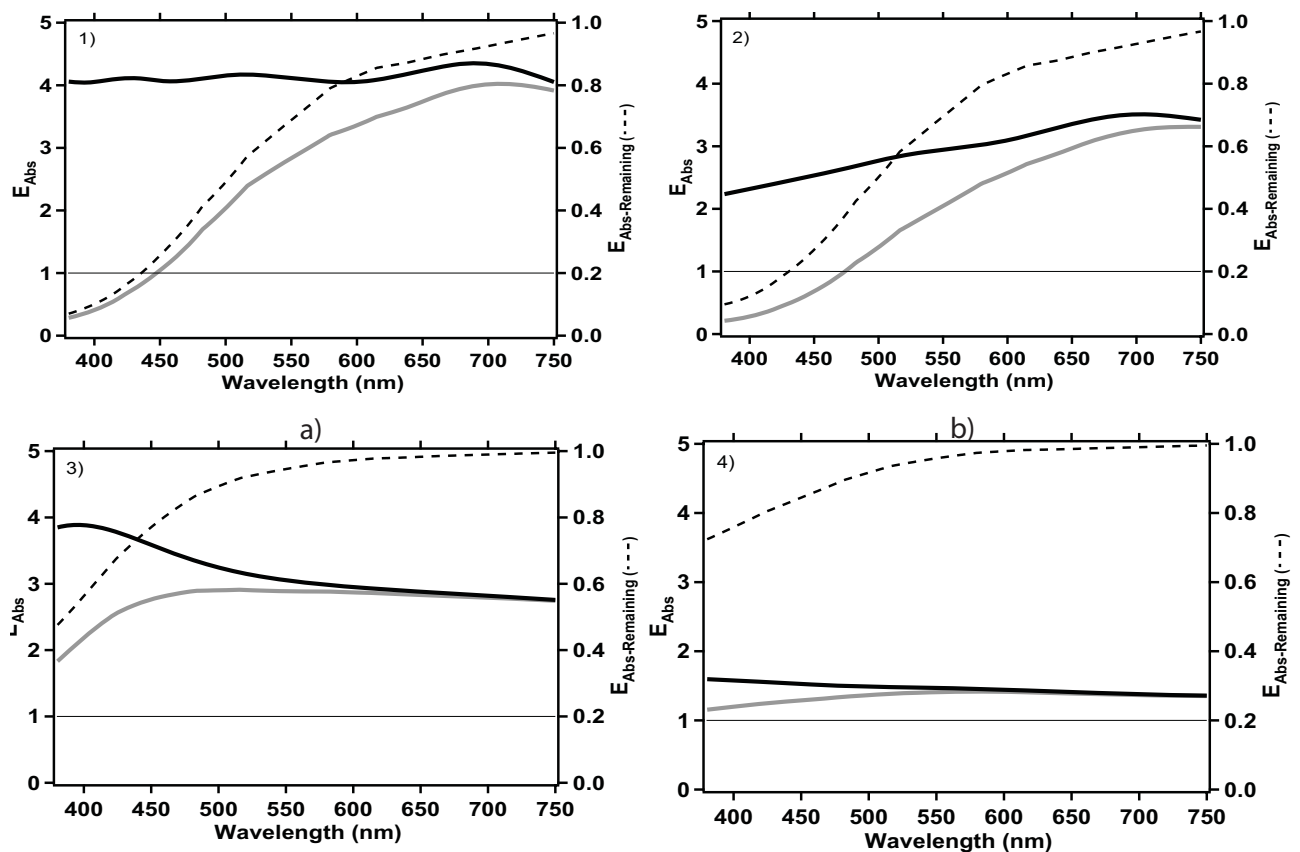

c)

d)

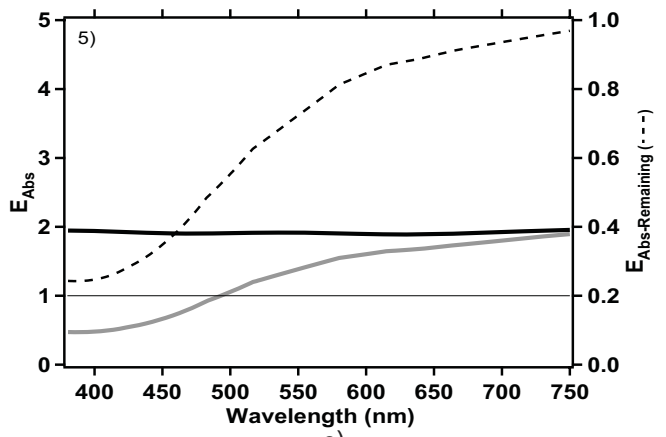

e)

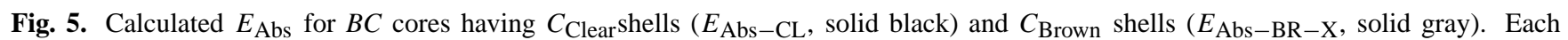
numbered panel corresponds to the central conditions of the numbered regimes in Bond et al. (2006). The dashed line shows $E_{\mathrm{Abs}-\mathrm{Remaining}}$

$\left(d_{\text {core }} / d_{\text {shell }}>0.55\right)$ on cores of all sizes. Regime numbers are labeled in Fig. 4 and the central core and shell diameters used elsewhere in the text (e.g. Table 1) are indicated by the position of the numbers of each regime in Fig. $4 \mathrm{a}$.

\subsection{Impact of $C_{\text {Brown }}$ shell thickness and $B C$ core size}

For a given wavelength and $k_{\text {Brown }}$, as the thickness of the $C_{\text {Brown }}$ shell increases $E_{\mathrm{Abs}}$ decreases. For example, for $400 \mathrm{~nm}$ wavelength radiation in regimes 3 and 4 (Fig. 4a), $E_{\text {Abs }}$ loss can be up to $50 \%$. For very thin shells (regime 4 ) the $E_{\mathrm{Abs}}$ loss can be up to $10 \%$ and as shell thickness decreases, the $C_{\text {Brown }}$ coating behaves more like $C_{\text {Clear }}$. For much thicker shells $E_{\mathrm{Abs}}$ can be reduced by $80 \%$ or more (i.e. in regimes 1, 2 or 5). When averaged across all visible wavelengths (from 380-750 nm, Fig. 4b) the $E_{\mathrm{Abs}}$ loss is $15-20 \%$ in regimes 3 and 4 and $\sim 30-50 \%$ in regimes 1,2 and 5 . The difference between $400 \mathrm{~nm} E_{\mathrm{Abs}}$ and the wave- length averaged $E_{\mathrm{Abs}}$ results from the assumed wavelength dependence of absorption by $C_{\text {Brown }}$. The $E_{\mathrm{Abs}}$ loss depends only weakly on $B C$ core size (Fig. 4), indicating that for a given wavelength (i.e. $k_{\mathrm{Brown}}$ ), the $E_{\mathrm{Abs}}$ loss is predominantly a function of the amount of $C_{\text {Brown }}$.

\subsection{Core shell regimes from Bond et al. (2006)}

Here we use core and shell diameters that form the central value of each of the five Bond et al. (2006) regimes (Fig. $4 \mathrm{a}$ and Table 1) and the central values for $k_{\text {Brown }}$ from Fig. 2 to gain further insight into the effect of $C_{\text {Brown }}$ on $E_{\mathrm{Abs}}$. Figure 5 presents these results with regime numbers given in the top left of each plot. As discussed above it is clear that $E_{\mathrm{Abs}}$ is reduced for very thick $C_{\text {Brown }}$ shells (Fig. 5a, b and e). It is also evident that not only does the $C_{\text {Brown }}$ shell reduce the number of additional photons being directed to the core (i.e. reduction in lensing), but sufficiently thick $C_{\text {Brown }}$ 


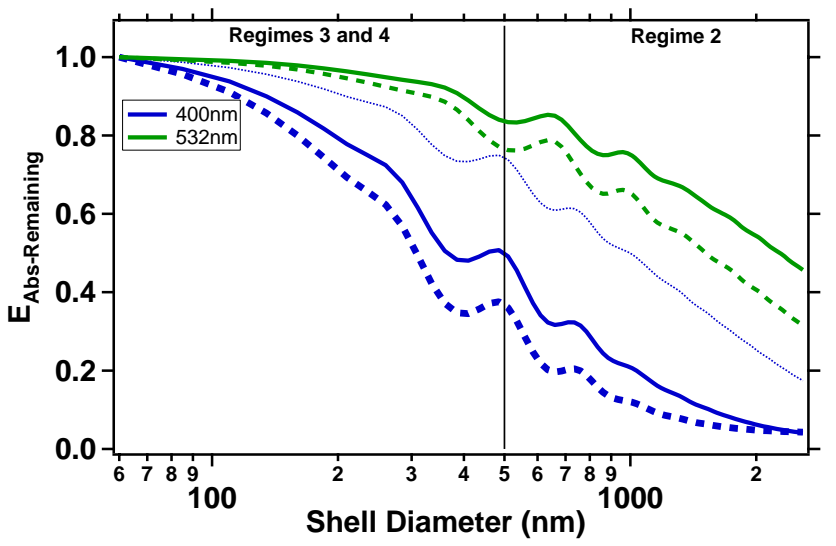

Fig. 6. Calculated $E_{\mathrm{Abs}-\text { Remaining }}$ for a $60 \mathrm{~nm}$ diameter $B C$ core and varying $C_{\text {Brown }}$ shell diameters at $400 \mathrm{~nm}$ and $532 \mathrm{~nm}$ wavelength for high (thick dashed line), mid (solid black line) and low (thin dashed line) $k_{\text {Brown }}$ values corresponding to Fig. 2.

shells also prevent photons from reaching the $B C$ core. This is evidenced by $E_{\mathrm{Abs}-\mathrm{BR}-\mathrm{X}}$ reaching below 1 and progressing towards zero at short wavelengths where absorption by $C_{\text {Brown }}$ is assumed to become large (this would indicate no photons reaching the core). However, $E_{\mathrm{Abs}-\mathrm{BR}-\mathrm{X}}$ only goes to zero for regimes 1,2 and 5, which were described as generally unrealistic in the atmosphere. Within the more realistic regimes (regimes 3 and 4, Fig. 5c, d) $E_{\mathrm{Abs}}$ is reduced from the clear coating case by $30-50 \%$ at $400 \mathrm{~nm}$ wavelength but $E_{\mathrm{Abs}-\mathrm{BR}-\mathrm{X}}$ remains $>1$ indicating that the lensing effect is still occurring despite the attenuation of photons by the $C_{\text {Brown }}$ material.

\subsection{Impact of Imaginary RI of $C_{\text {Brown }}$}

The results presented so far are calculated with an assumed $k_{\text {Brown }}$, based on experimental and theoretical results (Kirchstetter et al., 2004; Barnard et al., 2008; Sun et al., 2007). A wide range of both imaginary $R I$ and $M A C$ for $C_{\text {Brown }}$ have been found and so here we investigate the sensitivity of $E_{\text {Abs }}$ loss to the assumed $k_{\text {Brown }}$. Using the ranges of $k_{\text {Brown }}$ from Fig. 2 we model the $E_{\mathrm{Abs}-\text { Remaining }}$ for a $60 \mathrm{~nm}$ diameter $B C$ core (central core diameter of regime 3 ) coated in $C_{\text {Brown }}$ at $400 \mathrm{~nm}$ and $532 \mathrm{~nm}$ wavelength. Figure 6 shows $E_{\text {Abs-Remaining }}$ as a function of particle diameter and $k_{\text {Brown }}$. In these simulations, increasing the $400 \mathrm{~nm} k_{\text {Brown }}$ from the lower bound $k_{\text {Brown }}(0.02)$ (similar to the $k_{\text {Brown }}$ reported by Dinar et al. 2008) to the base case $k_{\text {Brown }}(0.05)$ increases the $E_{\text {Abs }}$ loss by 20-30\%. Increasing the $k_{\text {Brown }}$ from the base case by $50 \%$ (from 0.05 to 0.075 ; again, near that measured by Dinar et al., 2008) increases the $E_{\mathrm{Abs}}$ loss by a further $10-15 \%$. At $532 \mathrm{~nm}$, an increase in $k_{\text {Brown }}$ leads to an increase in the $E_{\mathrm{Abs}}$ loss of only a few percent for reasonable coating thicknesses $(<500 \mathrm{~nm})$ but leads to larger increases when very thick coatings are present. Further calculations (not shown) indicate that this conclusion is generally independent of the $B C$ core diameter used.

\subsection{Consideration of mixing state}

Even though $E_{\mathrm{Abs}-\mathrm{BR}}$ can be large under some conditions (e.g. when $C_{\text {Brown }}$ coatings are thick), our focus has been on the influence of $C_{\text {Brown }}$ on the lensing effect. It has tacitly been assumed that absorption by $C_{\mathrm{Brown}}$, whether considered as an internal or external mixture with $B C$, would be accounted for and quantified (for example in models) by the mass and $M A C$ of the $C_{\text {Brown }}$. We now consider how a reduction in the lensing effect (due to $C_{\text {Brown }}$ ) for an internal mixture will influence the $S S A$ and how this compares to an external mixture of $B C$ and $C_{\text {Brown. }}$. A reduction in lensing means that the fraction of absorption due to the $B C$ core will be reduced and, depending on how the contribution from $C_{\text {Brown }}$ is considered in a model, this may lead to uncertainty in the calculated SSA, which is the primary parameter that determines the sign of the radiative forcing by particles. For example, Jacobson $(2000,2001)$ showed that failure to consider the lensing effect due to clear coatings (i.e. treatment of the aerosol population as an external rather than an internal mixture) may lead to an underestimation of the radiative forcing of $B C$ by a factor of 2-3. However, if the lensing effect is reduced due to absorption by $C_{\text {Brown }}$ then this underestimation of radiative forcing will be similarly reduced, with the actual reduction dependent on the assumed wavelength dependence of the $C_{\text {Brown }}$.

\subsubsection{Mixing state assumptions and Single Scatter Albedo (SSA)}

One way to interpret the lensing effect is to recognize that it corresponds to a decrease in the SSA when compared to an equivalent mass external mixture. We have calculated the difference in SSA values between an external and an internal mixture of $B C$ and $C_{\text {Brown }}$ (at $400 \mathrm{~nm}$ assuming a $k_{\text {Brown }}$ of 0.05 and $\mathrm{GSD}=1.1$ ) and similarly for $B C$ and $C_{\text {Clear }}\left(\triangle S S A_{\text {ext-int }}=S S A_{\text {ext }}-S S A_{\text {int }}\right.$, where the ext and int indicate external and internal mixtures, respectively; Fig. 7). For the $C_{\text {Brown }}$ case (Fig. $\left.7 \mathrm{a}\right)$, at small core sizes $(<50 \mathrm{~nm})$ the difference between the internal and external mixture $S S A$ values is small $(<0.03)$. For the $C_{\text {Clear }}$ case, for small core sizes certain coating thicknesses will give somewhat larger $\triangle S S A$ (see Fig. 7b), but for most core/shell combinations $\triangle S S A_{\text {ext-int }}$ is small. Additionally, $\triangle S S A_{\text {ext-int }}$ is small when the coating is very thick (i.e. within regimes 1 and 2). However, for larger assumed $B C$ core sizes the difference can become large, especially for intermediate coating thicknesses. This indicates that even though the $E_{\mathrm{Abs}}$ is generally largest for small $B C$ cores and/or very thick coatings (c.f. Fig. 5 in Bond et al., 2006), in these regimes accurate specification of the mixing state will not strongly influence the radiative properties of $B C$ and $C_{\text {Brown }}$. We have also 

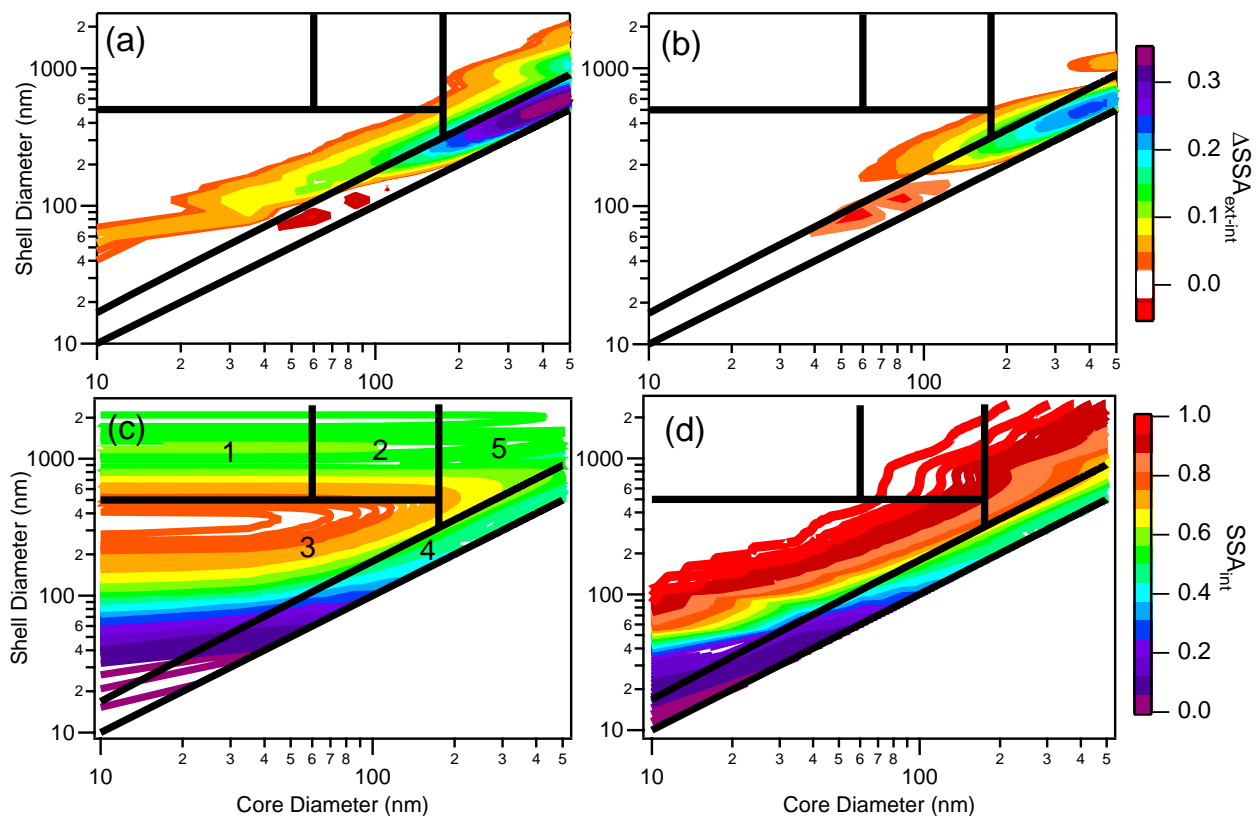

Fig. 7. Contour plots of the calculated difference in the $S S A$ between an external mixture and an internal mixture for a coated $B C$ particle

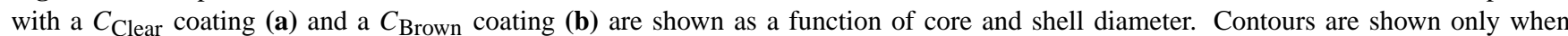
$\left|\Delta S S A_{\text {ext-int }}\right|>0.03$. The color scale shown applies to both graphs. The actual SSA for the $B C / C_{\mathrm{Clear}}(\mathbf{c})$ and $B C / C_{\mathrm{Brown}}(\mathbf{d})$ internal mixtures are shown for reference. Note that absorption by the $C_{\mathrm{Brown}}$ shell narrows the size region over which large differences between the internal and external mixture are found.

repeated these calculations at longer wavelengths $(532 \mathrm{~nm}$ and $700 \mathrm{~nm}$ ) and find that the general discussion given above remains valid even though the imaginary refractive index for $C_{\text {Brown }}$ is smaller than at $400 \mathrm{~nm}$. The main influence of mixing state in these regimes is to increase the overall particle size (i.e. cross section), which will tend to increase the total light extinction, but this will have minimal influence on the balance between absorption and scattering. However, when larger $B C$ core sizes are used within a model, mixing state is seen to be an important factor. This is generally true whether $C_{\text {Brown }}$ or $C_{\text {Clear }}$ coatings are considered, although for $C_{\text {Brown }}$ coatings the importance of mixing state is lessened (consistent with the reduction in the lensing effect identified above).

\subsubsection{Mixing state and micro-physical model assumptions}

To our knowledge, no atmospheric models explicitly account the fact that $B C$ is actually a fractal agglomerate composed of many small (10's of nm in diameter) spherules (van Poppel et al., 2005). $B C$ is instead represented as spherical particles of some size (or with some size distribution), and the optical properties are calculated based on the spherical particle size. Rayleigh-Debye-Gans $(R D G)$ theory posits that for a fractal particle such as $B C$ the absorption behavior is instead dictated by the size of the individual (small) spherules, and not by the agglomerated particle as a whole, i.e. that absorption is additive (Sorensen, 2000). If coated $B C$ particles should be treated in accordance with $R D G$ theory (i.e. as aggregates of 20-30 $\mathrm{nm}$ spheres), rather than as larger spherical particles, then the above discussion suggests that the importance of treating $B C$ as an internal mixture may be limited in terms of the direct radiative effects even though $E_{\mathrm{Abs}}$ may be relatively large. However, the fact that models tend to use $B C$ particles with relatively large diameters (i.e. $>80 \mathrm{~nm}$ ) (e.g. Kinne et al., 2003) means that the calculated radiative properties may be particularly sensitive to the choice and representation of $B C$ mixing state.

In part, it is for the above reasons that we believe it remains a useful exercise to consider core-shell Mie theory results using $B C$ core diameters that go beyond the typical spherule size range when calculating $E_{\mathrm{Abs}}, S S A$ and $A A E$ values for coated $B C$ particles. Furthermore, what few experimental measurements that exist of $E_{\mathrm{Abs}}$ for coated soot appear more consistent with the soot particles being single large spheres rather than small spherules (Schnaiter et al., 2003; Zhang et al., 2008). Additionally, $A A E$ values $<1$ are routinely observed in ambient measurements (Bergstrom et al., 2007; Lack et al., 2008), a result that is theoretically predicted for $B C$ spheres that are larger than $\sim 150 \mathrm{~nm}$. Certainly more work is necessary to establish what the appropriate core size is for use in $E_{\mathrm{Abs}}$ and $A A E$ calculations in order to facilitate both interpretation of ambient measurements and accurate calculation of the radiative effects of $B C$ (and $C_{\text {Brown }}$ ) in models. 


\subsection{Absorption wavelength dependence}

The wavelength dependence of absorption is typically characterized by the absorption Angstrom exponent (AAE, Eq. 2). For "pure" $B C$ in the atmosphere the $A A E$ is assumed to be 1 (Bond and Bergstrom, 2006) and observations of $A A E>1$ are often taken as evidence of $C_{\text {Brown }}$ (or dust). In actuality, for $A A E=1$ the $B C$ must be of sufficiently small diameter (e.g. $10 \mathrm{~nm}$ ) or, following from $R D G$ theory, a $B C$ core must be a fractal agglomerate composed of many sufficiently small individual spherules. As discussed above, some ambient data provides evidence of large $B C$ cores (i.e. with $A A E$ of $<1$ ). In addition, $A A E$ values $>1$ are theoretically possible for $B C$ coated in $C_{\text {Clear }}$ (not $C_{\text {Brown }}$ ) as discussed in Gyawali et al. (2009). Therefore, an assumed $A A E=1$ to anchor $B C$ absorption, and attribute $C_{\text {Brown }}$ absorption contains significant potential errors.

\subsubsection{AAE variability of $B C$ with $C_{\text {Clear }}$}

Here we extend the calculations of Gyawali et al. (2009) in order to make clearer the need for caution in the use of the $A A E$ when attributing light absorption to $C_{\text {Brown }}$. Fig-

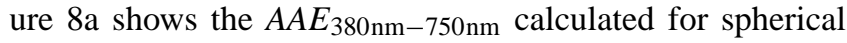
$B C$ cores coated in various thicknesses of $C_{\text {Clear }}$. The $R I$ used are the same as presented in the sections above, while a larger GSD of 1.7 is assumed for the $L N$ distribution, which represents a particle size distribution from biofuel or biomass combustion (Bond et al., 2006). Figure 8a shows that the $A A E_{380 \mathrm{~nm}-750 \mathrm{~nm}}$ for $B C$ cores coated in $C_{\text {Clear }}$ is reasonably constant within 4 of the 5 core-shell regimes (regimes 1-3 and 5). Regime 4 (thin coatings on all core

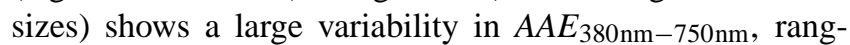
ing from -0.2 to 1.7 , similar to the $A A E$ behavior of uncoated $B C$. For the other "realistic" regime (regime 3), the

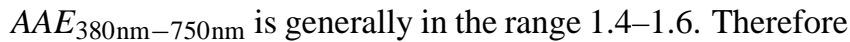
one can only attribute absorption to $C_{\mathrm{B} \text { rown }}$ with confidence if

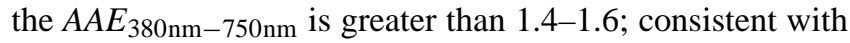
the findings of Gyawali et al. (2009).

\subsubsection{AAE Variability of $B C$ with $C_{\text {Brown }}$}

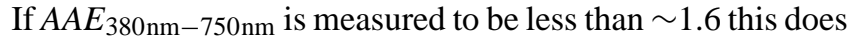
not necessarily rule out $C_{\text {Brown }}$ as a significant contributor to the observed absorption. For certain core/shell size pair-

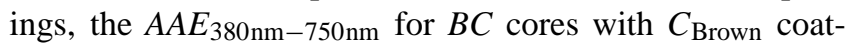
ings can actually be close to (or even less than) unity, dependent upon the assumed $k_{\text {Brown }}$. We consider this in more detail by determining how the $A A E_{380 \mathrm{~nm}-750 \mathrm{~nm}}$ depends on the assumed $k_{\text {Brown }}$ for $C_{\text {Brown }}$ coatings on $B C$ cores. This is important to consider because, even if $k_{\text {Brown }}$ is large, only in certain regions (e.g. downwind of a forest fire) will the ambient aerosol be predominately composed of $B C$ and OC. More common will be situations where inorganic ions (or non-absorbing $O C$ ) also contribute to the aerosol bur-
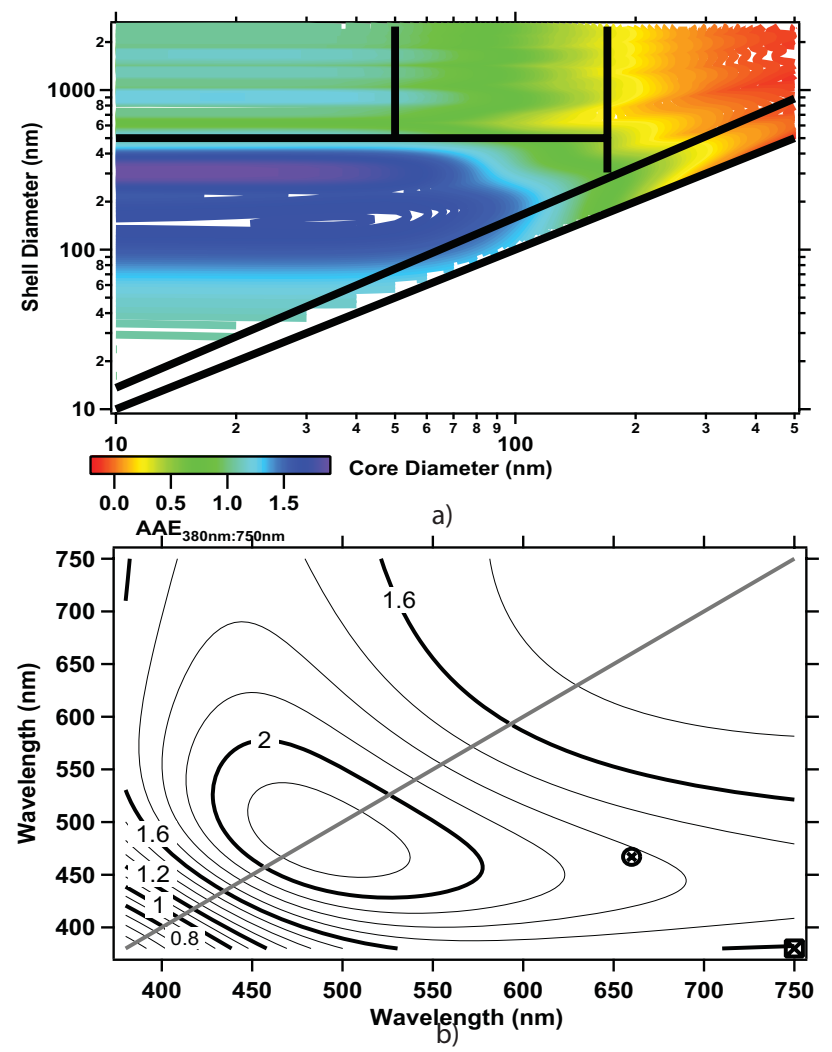

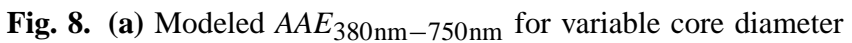
and $C_{\text {Clear }}$ shell thicknesses. (b) Modeled $A A E$ as a function of wavelength choice for a $60 \mathrm{~nm}$ core and $330 \mathrm{~nm}$ diameter coating (central values of regime 3 ). The black square and black circle indicates wavelength combinations used in this study and Bergstrom et al. (2007) respectively.

den, thus decreasing the effective imaginary $R I$ of the coating. As expected, the relationship between $A A E_{380 \mathrm{~nm}-750 \mathrm{~nm}}$ and $k_{\text {Brown }}$ depends explicitly on the core and shell diameters (Fig. 9). We have investigated three specific cases where the shell/core ratio has been varied; case 1: $d_{p \text {, particle }} / d_{p \text {, core }}=2$; case 2: $d_{p \text {, particle }} / d_{p, \text { core }}=3$; case $3: d_{p \text {, particle }} / d_{p \text {, core }}=4$. This equates to shell/core volume ratios of 7, 26 and 63, respectively. For comparison, $B C$ has often been found in ambient samples to be ca. 5-10\% of the total particle mass (Quinn et al., 2002; Quinn et al., 2004), corresponding approximately to cases 1 and 2 , although $B C$ mass fraction can vary greatly depending on proximity to sources.

Considering Case 1 (Fig. 9a), it is apparent that for many

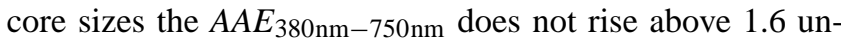
til the $k_{\text {Brown }}$ is at least $>0.03$ and for $d_{p \text {,core }} \geq 125 \mathrm{~nm}$ the $A A E_{380 \mathrm{~nm}-750 \mathrm{~nm}}$ is not $>1.6$ even when $k_{\text {Brown }}=0.06$. However, for particles with $50 \mathrm{~nm} \leq d_{p \text {,core }} \leq 100 \mathrm{~nm}$ the $A A E$ is noticeably greater than 1.6 after $k_{\text {Brown }}>0.02$. Thus, in a region where the coatings on $B C$ particles are relatively thin it is necessary to have relatively large $k_{\text {Brown }}$ in order to confidently distinguish contributions of $C_{\mathrm{Brown}}$ from the generic 

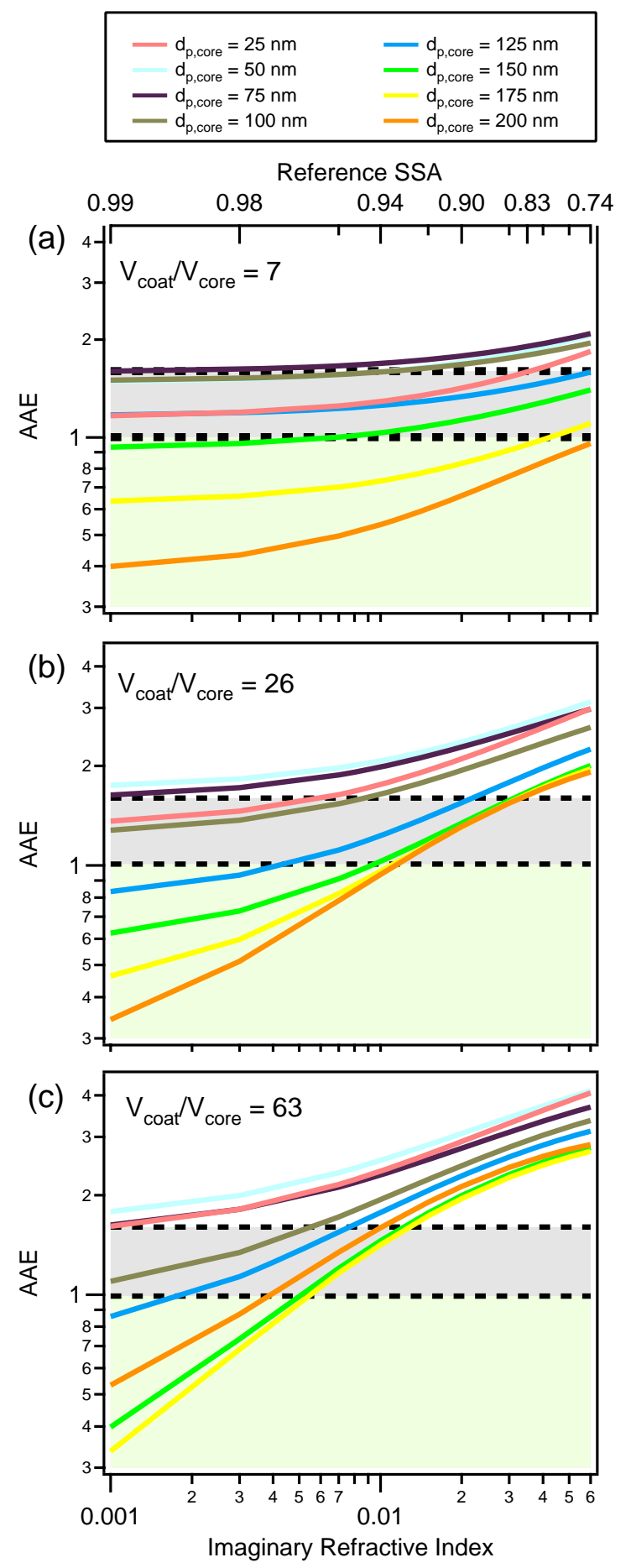

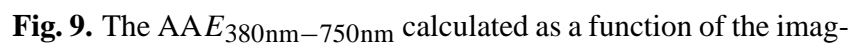
inary RI for different assumed $B C$ core diameters (indicated by the different color lines) and $C_{\text {Brown }}$ shell thicknesses. Calculations

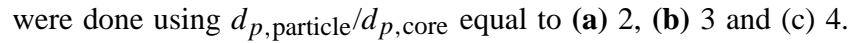
The corresponding volume ratios are given on the figure. For reference, the SSA values associated with the given imaginary refractive indices are shown on the top axis (calculated for a $d_{p}=200 \mathrm{~nm}$ particle at $380 \mathrm{~nm}$ ). The gray regions in all panels indicates the area where $1<\mathrm{AA} E_{380 \mathrm{~nm}-750 \mathrm{~nm}}>1.6$ and the green region where $\mathrm{AA} E_{380 \mathrm{~nm}-750 \mathrm{~nm}}<1$. influence of $C_{\text {Clear }}$ coatings on the $A A E$. As the shell/core volume ratio is increased the minimum $k_{\text {Brown }}$ needed to give $A A E_{380 \mathrm{~nm}-750 \mathrm{~nm}}>1.6$ is reduced. For example, for Case 3 the minimum $k_{\text {Brown }}$ is $\sim 0.01$ for all core diameter sizes considered. This is because as the coating amount is increased the absorption due to the coating (as opposed to the core) is increased in proportion. Thus, for regions where the coatings on $B C$ particles are thick it may be possible to readily identify $C_{\text {Brown }}$ through the $A A E$.

The above discussion focuses on what conditions will allow for attribution of $C_{\text {Brown }}$ to observed absorption. However, Fig. 9 also indicates that observation of $A A E$ values around 1 does not definitively indicate that absorption is due to $B C$ only. Instead, it is found that relatively significant absorption by $C_{\text {Brown }}$ can still result in $A A E$ values around 1. (Note that "significant" does not have a precise definition. Here we arbitrarily interpret significant to mean the minimum $k_{\text {Brown }}$ needed to give a calculated $S S A_{380 \mathrm{~nm}}>0.95$ for a $200 \mathrm{~nm} d_{p} C_{\text {Brown }}$ particle. Thus, with this definition we see that significant absorption by $C_{\text {Brown }}$ occurs when $k_{\text {Brown }} \geq 0.01$. This value can be compared to the $k_{\text {Brown }}$ that would give a "noticeable" deviation in the SSA from unity (i.e. $S S A<0.98$ ), which occurs for $k_{\text {Brown }}>0.003$. For reference, the $S S A$ values corresponding to a particular $k_{\text {Brown }}$ for these $200 \mathrm{~nm}$ particles are shown in Fig. 9.) Consistent with the above discussion, significant contributions of $C_{\text {Brown }}$ to absorption that still result in $A A E_{380 \mathrm{~nm}-750 \mathrm{~nm}} \sim 1$ are most common for thinner coatings but still have a reasonable probability of occurring for thicker coatings. And in the absence of specific knowledge about the actual $B C$ size distribution and coating thickness from measurements it is really more appropriate to consider the $A A E_{380 \mathrm{~nm}-750 \mathrm{~nm}}$ limit of 1.6 (instead of 1), in which case it is difficult to rule out contributions of $C_{\text {Brown }}$ to observed absorption for nearly any reasonable core/shell combination. However, if simultaneous measurements of the total particle size distribution, $B C$ size distribution and/or the $B C$ mass fraction are made the aboveidentified limitations on $C_{\text {Brown }}$ identification may be relaxed somewhat. This is because then one would know where on the $d_{p \text {, coat }}$ vs. $d_{p \text {, core }} A A E$ contour the measurements should be compared.

\subsubsection{Comparing modeled AAE with ambient measurements}

Although an $A A E$ of 1.6 is not an absolute reference point, especially given the results from 4.5.2, at the wavelengths considered here it does serve as a general first approximation and lower limit to $A A E$ for absolute attribution of $C_{\text {Brown }}$. With this in mind, it is interesting to consider that almost $90 \%$ of $A A E$ measurements over 2 months of ambient sampling during the GoMACCS field campaign (SE USA, Bates et al., 2008) were less than 1.6 (Bergstrom et al., 2007). Additionally, our own analysis indicates that $A A E$ values during the 2002 and 2004 NEAQS campaigns (NE USA, Bates 
et al., 2005; Sierau et al., 2006) were less than $1.6 \sim 75 \%$ and $100 \%$ of the time, respectively. The campaign average

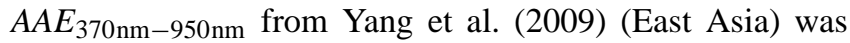
$1.46( \pm 0.27)$ and was only $1.49( \pm 0.08)$ during periods identified as being influenced by biomass burning, where $C_{\text {Brown }}$ is expected. Favez et al. (2009) sampled agricultural biomass combustion and rareley saw $A A E>1.5$ in over a week of sampling. Again, these are combustion conditions where contributions from $C_{\text {Brown }}$ are somewhat expected. Gyawali et al. (2009) found that the $A A E_{405 \mathrm{~nm}-870 \mathrm{~nm}}$ during a month very strongly impacted by biomass burning fires was above the 1.6 limit $\sim 75 \%$ of the time ( $60 \%$ after accounting for the uncertainty in the measurements). Although differences in particle morphology may contribute to the observed variability in these ambient $A A E$ observations, taken all together this indicates that very few ambient $A A E$ measurements (in the diverse regions studied) are above the 1.6 limit and therefore cannot provide certain $C_{\text {Brown }}$ attribution (at least in the absence of more specific knowledge of the core and shell sizes during the measurement periods). However, at the same time none of these observations can rule out the possibility that $C_{\text {Brown }}$ is a pervasive contributor to sub-micron aerosol light absorption.

Therefore, when attempting to investigate the impact of $C_{\text {Brown }}$ on $A A E$ it is important to consider to some degree the underlying core shape, spherule density, shell diameter, mixing state and SSA before any reliable quantification can be undertaken. The difficulty in simultaneously quantifying these parameters in ambient experiments, particularly core shapes, spherule densities and coating thickness will be a challenging task. Related to this is whether in-situ filterbased methods of measuring absorption appropriately represent $A A E$. Given that $A A E$ is sensitive to both $C_{\text {Clear }}$ and $C_{\text {Brown }}$ coating thickness and that there is some evidence that filter based methods suffer from biases under elevated OC content (Cappa et al., 2008; Kondo et al., 2009; Lack et al., 2008), caution must be applied to these measurement methods and the derived parameters such as $A A E$. It must also be noted here that that the $A A E$ is dependent on the choice of wavelengths (as shown in Fig. 8b). Our discussion above is based on $380 \mathrm{~nm}$ and $750 \mathrm{~nm}$ radiation, the extreme wavelengths of the visible light spectrum.

\subsubsection{Measurement and analysis of ambient $A A E$}

As a final consideration, we mention that care must be taken in extracting $A A E$ values from measurements when absorption is measured at more than two wavelengths. In addition to Eq. (2), $A A E$ values have been determined from the linearfit slope of a log-log plot of absorption vs. wavelength (e.g. Bergstrom et al., 2007). When there are many wavelengths considered (such as from sun photometer measurements), it is likely that the fitting method will give "good" results. However, if absorption is measured at only three wavelengths (as is commonly done from in-situ measurements) the fit re- sults can give both qualitative and quantitatively different results than if wavelength pairs are used (Eq. 2). Take as an example the laboratory measurements of Schnaiter et al. (2005) where the influence of coatings of $\alpha$-pinene + ozone SOA on $B C$ absorption was investigated. Based on the fitting method, they reported that the addition of the $S O A$ coatings led to a decrease in the $A A E$, from 1.13 for uncoated $B C$ to 0.8 for thickly coated $B C$. In contrast, we estimate (from their Fig. 9) that if the $A A E$ had instead been determined using Eq. (2), it would have been found to increase with the addition of $S O A$ coatings, from $\sim 0.8$ to 1.5 (for $450 \mathrm{~nm}-550 \mathrm{~nm}$ ) and from $\sim 0.9$ to 1.2 (for $450 \mathrm{~nm}-700 \mathrm{~nm}$ ). Thus, any discussion of $A A E$ 's deduced from measurement must always be considered in the context of the analysis methodology.

\section{Summary, conclusions and recommendations}

Purely scattering shells on black carbon $(B C)$ cores can significantly enhance the absorption by that core as a result of focusing of light towards the $B C$ core by the shell material (Bond et al., 2006). However, if those shells are mildly absorbing $\left(C_{\mathrm{Brown}}\right)$ this enhancement $\left(E_{\mathrm{Abs}}\right)$ can be reduced, with the specific extent of reduction dependent upon the radiation wavelength, imaginary RI $\left(k_{\text {Brown }}\right)$ and thickness of the shell. Estimates of the absorption strength of $C_{\text {Brown }}$ from the literature are highly variable, likely depending on the $C_{\text {Brown }}$ source and composition; certainly further research is required to fully understand this variability as the overall climate impacts of $C_{\text {Brown }}$ will depend importantly on the exact wavelength dependence of the absorption (e.g. Flores et al., 2009). Nonetheless, using a mid-range estimate for $k_{\text {Brown }}$ we have shown, using core/shell Mie theory calculations, that $E_{\mathrm{Abs}}$ can be reasonably reduced from the clear coating case by up to $50 \%$ at $400 \mathrm{~nm}$ radiation and up to $25-30 \%$ averaged across the visible radiation spectrum. This could be a significant reduction of predicted $E_{\mathrm{Abs}}$ depending on the ubiquity of $C_{\mathrm{Brown}}$. The $E_{\mathrm{Abs}}$ reduction is sensitive to both the thickness of the $C_{\text {Brown }}$ shell and the $k_{\text {Brown }}$ but is relatively insensitive to $B C$ core size for a given coating thickness. At the extreme limit of thick $C_{\text {Brown }}$ shells and shorter visible wavelengths, the $C_{\mathrm{Brown}}$ can eliminate $E_{\mathrm{Abs}}$ entirely by completely shielding the $B C$ core from photons.

We have also assessed the importance of considering $C_{\text {Brown }}$ as an internal mixture with $B C$, as opposed to an external mixture, in terms of the effect on the particle single scatter albedo (SSA), and ultimately the direct radiative forcing. Large differences in the calculated SSA between the internal and external mixtures are only found when large $B C$ cores are used. When small $B C$ cores are used (or if it is assumed that the larger particles are actually aggregates of small individual spherules) the SSA differences are found to be minor $(\triangle S S A<0.03)$. However, compared to the clear coating case, the potential mis-representation of the radiative forcing by not including the absorption enhancement effect 
(i.e. external mixtures) is lessened due to the reduced lensing impact of $C_{\text {Brown }}$.

The absorption Angstrom exponent $(A A E)$ is often used to identify atmospheric contributions of $C_{\text {Brown }}$ to visible light absorption from ambient particle optical property measurements. Generally, this is done by assuming that only $C_{\text {Brown }}$ and dust have $A A E>1$ and thus that any observation of $A A E>1$ indicates the presence of $C_{\text {Brown }}$ and/or dust. However, the $A A E$ for $B C$ cores can vary around $1(-0.2$, +1.3 ) with significant deviations from 1 occurring for assumed larger diameters, where it is uncertain if the $B C$ exists as a dense spherical particle. For $B C$ particles coated in purely scattering material it is possible to obtain $A A E$ values significantly greater than 1 , with values as large as 1.6 common (for the specific wavelength pairs considered here). Thus, attribution of $C_{\text {Brown }}$ to the observed absorption can only be made with confidence if the $A A E$ is measured to be $>1.6$. Conversely, we have shown that the measurement of $A A E$ values close to 1 does not rule out significant contributions from $C_{\text {Brown }}$ to absorption. Our calculations suggest that attempts to quantitatively (or even qualitatively) attribute light absorption to $C_{\text {Brown }}$ from measurement of the wavelength dependence of absorption will be most successful if conducted concurrent with measurements of $B C$ and total particle size distributions.

Acknowledgements. Funded through NOAA's Atmospheric Composition and Climate Program within the Climate Program Office.

Edited by: L. M. Russell

\section{References}

Abo Riziq, A., Trainic, M., Erlick, C., Segre, E., and Rudich, Y.: Extinction efficiencies of coated absorbing aerosols measured by cavity ring down aerosol spectrometry, Atmos. Chem. Phys., 8, 1823-1833, 2008, http://www.atmos-chem-phys.net/8/1823/2008/.

Adler, G., Abo Riziq, A., Erlick, C., and Rudich, Y.: Effect of intrinsic organic carbon on the optical properties of fresh diesel soot, Proceedings of the National Academy of Sciences, Early Edition, doi:10.1073/pnas.0903311106, 2009.

Alexander, D. T. L., Crozier, P. A., and Anderson, J. R.: Brown Carbon Spheres in East Asian Outflow and their Optical Properties, Science, 321, 833-836, 2008.

Andreae, M. O. and Gelencser, A.: Black Carbon or Brown Carbon? The Nature of Light Absorbing Carbonaceous Aerosols, Atmos. Chem. Phys., 6, 3131-3148, 2006,

http://www.atmos-chem-phys.net/6/3131/2006/.

Barnard, J. C., Volkamer, R., and Kassianov, E. I.: Estimation of the Mass Absorption Cross Section of the Organic Carbon Component of Aerosols in the Mexico City Metropolitan Area, Atmos. Chem. Phys., 8, 6665-6679, 2008,

http://www.atmos-chem-phys.net/8/6665/2008/.

Bates, T. S., Quinn, P. K., Coffman, D. J., Johnson, J. E., and Middlebrook, A. M.: Dominance of organic aerosols in the marine boundary layer over the Gulf of Maine during NEAQS 2002 and their role in aerosol light scattering, J. Geophys. Res., 110, D18202, doi:10.1029/2005jd005797, 2005.

Bates, T. S., Quinn, P. K., Coffman, D. J., Schulz, K., Covert, D. S., Johnson, J. E., Williams, E. J., Lerner, B. M., Angevine, W. M., Tucker, S. C., Brewer, W. A., and Stohl, A.: Boundary Layer Aerosol Chemistry during TexAQS/GoMACCS 2006: Insights into Aerosol Sources and Transformation Processes, J. Geophys. Res., 113, D00F01, doi:10.1029/2008JD010023, 2008.

Bergstrom, R. W., Pilewskie, P., Russell, P. B., Redemann, J., Bond, T., Quinn, P. K., and Sierau, B.: Spectral Absorption Properties of Atmospheric Aerosols, Atmos. Chem. Phys., 7, 5937-5943, 2007, http://www.atmos-chem-phys.net/7/5937/2007/.

Bohren, C. F. and Huffman, D. R.: Absorption and Scattering of Light by Small Particles, John Wiley \& Sons, Inc, 530 pp., 1983.

Bond, T., Habib, G., and Bergstrom, R. W.: Limitations in the Enhancement of Visible Light Absorption Due to Mixing State, J. Geophys. Res., 111, D20211, doi:10.1029/2006JD007315, 2006.

Bond, T. C. and Bergstrom, R. W.: Light Absorption by Carbonaceous Particles: An Investigative Review, Aerosol Sci. Technol., 40, 27-67, 2006.

Cappa, C., Lack, D., Burkholder, J., and Ravishankara, A.: Bias in Filter Based Aerosol Light Absorption Measurements Due to Organic Aerosol Loading: Evidence from Laboratory Measurements, Aerosol Sci. Technol., 42, 1022-1032, 2008.

Clarke, A., McNaughton, C., Kapustin, V., Shinozuka, Y., Howell, S., Dibb, J., Zhou, J., Anderson, B., Brekhovskikh, V., Turner, H., and Pinkerton, M.: Biomass Burning and Pollution Aerosol over North America: Organic Components and Their Influence on Spectral Optical Properties and Humidification Response, J. Geophys. Res., 112, D12S18, doi:10.1029/2006jd007777, 2007.

Dinar, E., Abo Riziq, A., Spindler, C., Erlick, C., Kiss, G., and Rudich, Y.: The complex refractive index of atmospheric and model humic-like substances (HULIS) retrieved by a cavity ring down aerosol spectrometer (CRD-AS), Faraday Discussions, 137, 279-295, doi:10.1039/b703111d 2008.

Favez, O., Alfaro, S. C., Sciare, J., Cachier, H., and Abdelwahab, M. M.: Ambient measurements of light-absorption by agricultural waste burning organic aerosols, J. Aerosol Sci., 40, 613620, 2009.

Flores, J. M., Trainic, M., Borrmann, S., and Rudich, Y.: Effective broadband refractive index retrieval by a white light optical particle counter, Phys. Chem. Chem. Phys., 11, 7943-7950, 2009.

Fuller, K. A., Malm, W. C., and Kreidenweis, S. M.: Effects of Mixing on Extinction by Carbonaceous Particles, J. Geophys. Res., 104, 15941-15954, 1999.

Gustafsson, O., Krusa, M., Zencak, Z., Sheesley, R. J., Granat, L., Engstrom, E., Praveen, P. S., Rao, P. S. P., Leck, C., and Rodhe, H.: Brown Clouds over South Asia: Biomass or Fossil Fuel Combustion?, Science, 323, 495-498, doi:10.1126/science.1164857, 2009.

Gyawali, M., Arnott, W. P., Lewis, K., and Moosmueller, H.: In Situ Aerosol Optics in Reno, NV, USA During and After the Summer 2008 California Wildfires and the Influence of Absorbing and Non-Absorbing Organic Coatings on Spectral Light Absorption, Atmos. Chem. Phys., 9, 8007-8017, 2009, http://www.atmos-chem-phys.net/9/8007/2009/.

Hoffer, A., Gelencser, A., Guyon, P., Kiss, G., Schmid, O., Frank, G. P., Artaxo, P., and Andreae, M. O.: Optical Properties of Humic-like Substances (HULIS) in Biomass-Burning Aerosols, 
Atmos. Chem. Phys., 6, 3563-3570, 2006,

http://www.atmos-chem-phys.net/6/3563/2006/.

IPCC: Climate Change 2007: The Physical Science Basis. Contribution of Working Group 1 to the Fourth Assessment Report. Report of the Intergovernmental Panel on Climate Change, Cambridge University Press, Cambridge, UK and New York, NY, USA, 2007.

Jacobson, M. Z.: A Physically-Based Treatment of Elemental Carbon Optics: Implications for Global Direct Forcing of Aerosols, Geophys. Res. Lett., 27, 10.1029/1999g1010968, 2000.

Jacobson, M. Z.: Strong Radiative Heating due to the Mixing State of Black Carbon in Atmospheric Aerosols, Nature, 409, 695697, 2001.

Kinne, S., Lohmann, U., Feichter, J., Schulz, M., Timmreck, C., Ghan, S., Easter, R., Chin, M., Ginoux, P., Takemura, T., Tegen, I., Koch, D., Herzog, M., Penner, J., Pitari, G., Holben, B., Eck, T., Smirnov, A., Dubovik, O., Slutsker, I., Tanre, D., Torres, O., Mishchenko, M., Geogdzhayev, I., Chu, D. A., and Kaufman, Y.: Monthly Averages of Aerosol Properties: A Global Comparison Among Models, Satellite Data, and AERONET Ground Data, J. Geophys. Res., 108, D204634, doi:10.1029/2001jd001253, 2003.

Kirchstetter, T. W., Novakov, T., and Hobbs, P. V.: Evidence That the Spectral Dependence of Light Absorption by Aerosols is Affected by Organic Carbon, J. Geophys. Res., 109, D21208, 2004.

Kondo, Y., Sahu, L., Kuwata, M., Miyazaki, Y., Takegawa, N., Moteki, N., Imaru, J., Han, N. S., Nakayama, T., Kim-Oanh, N. T., Hu, M., Kim, Y. J., and Kita, K.: Stabilization of the Mass Absorption Cross Section of Black Carbon for Filter-Based Absorption Photometry by the Use of a Heated Inlet, Aer. Sci. Tech., 43, 741-756, doi:10.1080/02786820902889879, 2009.

Lack, D. A., Cappa, C. D., Covert, D. S., Baynard, T., Massoli, P., Sierau, B., Bates, T. S., Quinn, P. K., Lovejoy, E. R., and Ravishankara, A. R.: Bias in Filter Based Aerosol Light Absorption Measurements Due to Organic Aerosol Loading: Evidence from Ambient Measurements, Aerosol Sci. Tech., 42, 1033-1041, 2008.

Lack, D. A., Cappa, C. D., Cross, E. S., Massoli, P., Ahern, A. T., Davidovits, P., and Onasch, T. B.: Absorption Enhancement of Coated Absorbing Aerosols: Validation of the Photo-Acoustic Technique for Measuring the Enhancement, Aerosol Sci. Techol., 43, 1006-1012, 2009a.

Lack, D. A., Quinn, P. K., Massoli, P., Bates, T. S., Coffman, D., Covert, D. S., Sierau, B., Tucker, S., Baynard, T., Lovejoy, E. R., Murphy, D. M., and Ravishankara, A. R.: Relative Humidity Dependence of Light Absorption by Mineral Dust after LongRange Atmospheric Transport from the Sahara, Geophys. Res. Lett., 36, L24805, doi:10.1029/2009GL041002, 2009 b.

Lang-Yona, N., Abo-Riziq, A., Erlick, C., Segre, E., Trainic, M., and Rudich, Y.: Interaction of internally mixed aerosols with light, Phys. Chem. Chem. Phys., 12, 21-31, 2010.

Lewis, K. A., Arnott, W. P., Moosmuller, H., Chakrabarty, R. K., Carrico, C. M., Kreidenweis, S. M., Day, D. E., Malm, W. C., Laskin, A., Jimenez, J. L., Ulbrich, I. M., Huffman, J. A., Onasch, T. B., Trimborn, A., Liu, L., and Mishchenko, M. I.: Reduction in biomass burning aerosol light absorption upon humidification: roles of inorganically-induced hygroscopicity, particle collapse, and photoacoustic heat and mass transfer, Atmos. Chem. Phys., 9, 8949-8966, 2009, http://www.atmos-chem-phys.net/9/8949/2009/.

Liu, L., Mishchenko, M. I., and Patrick Arnott, W.: A study of radiative properties of fractal soot aggregates using the superposition T-matrix method, Journal of Quantitative Spectroscopy and Radiative Transfer, 109, 2656-2663, 2008.

Moteki, N., Kondo, Y., Miyazaki, Y., Takegawa, N., Komazaki, Y., Kurata, G., Shirai, T., Blake, D. R., Miyakawa, T., and Koike, M.: Evolution of Mixing State of Black Carbon Particles: Aircraft Measurements over the Western Pacific in March 2004, Geophys. Res. Lett., 34, L11803, doi:10.1029/2006g1028943, 2007.

Quinn, P. K., Coffman, D. J., Bates, T. S., Miller, T. L., Johnson, J. E., Welton, E. J., Neususs, C., Miller, M., and Sheridan, P. J.: Aerosol optical properties during INDOEX 1999: Means, variability, and controlling factors, J. Geophys. Res., 107, D198020, doi:10.1029/2000jd000037, 2002.

Quinn, P. K., Coffman, D. J., Bates, T. S., Welton, E. J., Covert, D. S., Miller, T. L., Johnson, J. E., Maria, S., Russell, L., Arimoto, R., Carrico, C. M., Rood, M. J., and Anderson, J.: Aerosol Optical Properties Measured Onboard the Ronald H. Brown During ACE-Asia as a Function of Aerosol Chemical Composition and Source Region, J. Geophys. Res., 109, D19S01, doi:10.1029/2003jd004010, 2004.

Rincon, A. G., Guzman, M. I., Hoffmann, M. R., and Colussi, A. J.: Optical Absorptivity versus Molecular Composition of Model Organic Aerosol Matter, J. Phys. Chem. A, 113, 10512-10520, doi:10.1021/jp904644n, 2009.

Roden, C. A., Bond, T. C., Conway, S., and Pinel, A. B. O.: Emission Factors and Real-Time Optical Properties of Particles Emitted from Traditional Wood Burning Cookstoves, Envi. Sci. Tech., 40, 6750-6757, doi:10.1021/es052080i, 2006.

Schnaiter, M., Linke, M., Möhler, O., Naumann, K.-H., Saathoff, H., Wagner, R., Schurath, U., and Wehner, B.: Absorption Amplification of Black Carbon Internally Mixed with Secondary Organic Aerosol, J. Geophys. Res., 110, D19204, doi:10.1029/2005JD006046, 2005.

Schnaiter, M., Gimmler, M., Llamas, I., Linke, C., Jager, C., and Mutschke, H.: Strong Spectral Dependence of Light Absorption by Organic Carbon Particles Formed by Propane Combustion, Atmos. Chem. Phys., 6, 2981-2990, 2006, http://www.atmos-chem-phys.net/6/2981/2006/.

Schwarz, J. P., Gao, R. S., Spackman, J. R., Watts, L. A., Thomson, D. S., Fahey, D. W., Ryerson, T. B., Peischl, J., Holloway, J. S., Trainer, M., Frost, G. J., Baynard, T., Lack, D. A., de Gouw, J. A., Warneke, C., and Del Negro, L. A.: Measurement of the Mixing State, Mass, and Optical Size of Individual Black Carbon Particles in Urban and Biomass Burning Emissions, Geophys. Res. Lett., 35, L13810, doi:10.1029/2008g1033968, 2008.

Schwier, A. N., Shapiro, E. L., Sareen, N., and McNeill, V. F. Secondary organic material formed by methylglyoxal in aqueous aerosol mimics - Part 1: Surface tension depression and lightabsorbing products, Atmos. Chem. Phys. Discuss., 9, 1554115565, doi:10.5194/acpd-9-15541-2009, 2009.

Shapiro, E. L., Szprengiel, J., Sareen, N., Jen, C. N., Giordano, M. R., and McNeill, V. F.: Light-Absorbing Secondary Organic Material Formed by Glyoxal in Aqueous Aerosol Mimics, Atmos. Chem. Phys., 9, 2289-2300, 2009, http://www.atmos-chem-phys.net/9/2289/2009/.

Shiraiwa, M., Kondo, Y., Iwamoto, T., and Kita, K.; Amplification of Light Absorption of Black Carbon by Organic Coating, 
Aerosol Sci. Technol., 44, 46-54, 2009.

Sierau, B., Covert, D. S., Coffman, D. J., Quinn, P. K., and Bates, T. S.: Aerosol Optical Properties During the 2004 New England Air Quality Study - Intercontinental Transport and Chemical Transformation: Gulf of Maine Surface Measurements Regional and Case Studies, J. Geophys. Res., 111, D23S37, doi:10.1029/2006jd007568, 2006.

Sorensen, C. M.: The Optics of Single Particles and Fractal Aggregates, J. Aer. Sci., 31, 952-954, 2000.

Sun, H., Biedermann, L., and Bond, T. C.: Color of Brown Carbon: A Model for Ultraviolet and Visible Light Absorption by Organic Carbon Aerosol, Geophys. Res. Lett., 34, 10.1029/2007g1029797, 2007.

van Poppel, L. H., Friedrich, H., Spinsby, J., Chung, S. H., Seinfeld, J. H., and Buseck, P. R.: Electron Tomography of Nanoparticle Clusters: Implications for Atmospheric Lifetimes and Radiative Forcing of Soot, Geophys. Res. Lett., 32, L24811, doi:10.1029/2005g1024461, 2005.

Yang, M., Howell, S. G., Zhuang, J., and Huebert, B. J.: Attribution of Aerosol Light Absorption to Black Carbon, Brown Carbon, and Dust in China, Interpretations of Atmospheric Measurements During EAST-AIRE, Atmos. Chem. Phys., 9, 2035-2050, 2009, http://www.atmos-chem-phys.net/9/2035/2009/.
Zhang, Q., Jimenez, J. L., Canagaratan, M. R., Allan, J. D., Coe, H., Ulbrich, I., Alfarra, M. R., Takami, A., Middlebrook, A. M., Sun, Y. L., Dzepina, K., Dunlea, E., Docherty, K., DeCarlo, P. F., Salcedo, D., Onasch, T., Jayne, J. T., Miyoshi, T., Shimono, A., Hatakeyama, S., Takegawa, N., Kondo, Y., Schneider, J., Drewnick, R., Borrmann, S., Weimer, S., Demerjian, K., Williams, P. I., Bower, K. N., Bahreini, R., Cottrell, L., Griffin, R. J., Rautiainen, J., Sun, J. Y., Zhang, Y. M., and Worsnop, D. R.: Ubiquity and Dominance of Oxygenated Species in Organic Aerosols in Anthropogenically-Influenced Northern Hemisphere Midlatitudes, Geophys. Res. Lett., 34, L13801, doi:10.1029/2007GL029979, 2007.

Zhang, R., Khalizov, A. F., Pagels, J., Zhang, D., Xue, H., and McMurry, P. H.: Variability in Morphology, Hygroscopicity, and Optical Properties of Soot Aerosols During Atmospheric Processing, Proc. Nat. Acad. Sci., 105, 10291-10296, 2008. 